\title{
Financial Risk Tolerance: The Case of Older Chinese in Klang Valley, Malaysia 2020
}

\author{
Shyue Chuan Chong ${ }^{1,2}$, Han Kok Heng ${ }^{1}$, Siok Jin Lim ${ }^{1}$, Vejaratnam Navaratnam ${ }^{1} \&$ Andaeus Zun Khan Neoh ${ }^{1}$ \\ ${ }^{1}$ Faculty of Accountancy, Management and Economics, New Era University College, Malaysia \\ ${ }^{2}$ Faculty of Accountancy, Finance and Business, Tunku Abdul Rahman University College, Malaysia \\ Correspondence: Shyue Chuan Chong, Faculty of Accountancy, Management and Economics, New Era University \\ College, Malaysia.
}

Received: October 11, 2020

Accepted: November 11, 2020

Online Published: January 11, 2021

doi:10.5430/ijfr.v12n2p1

URL: https://doi.org/10.5430/ijfr.v12n2p1

\begin{abstract}
Ageing demographic profiles pose challenges to the nation as policymakers are concerned about the health, public pension and the financial management of the society. In Malaysia, retirees are mostly dependent on savings from the Employees Provident Fund (EPF), a government agency that manages savings and retirement plans for private-sector employees and non-pensionable public servants. Many Malaysians aged past the targeted retirement age of 60 years old chose to remain in the workforce, mainly due to insufficient retirement funds or has depleted their retirement funds in a short period. To ensure sufficient funds to attain an ideal retirement life, Malaysians resort to invest or seek business opportunities. Thus, this paper studies the impact of demographic characteristics (sex, age, and educational level) and finance characteristics (financial knowledge and financial satisfaction) on the risk tolerance among older Malaysian Chinese in the year 2020. The results of this study showed that the older Malaysian Chinese risk tolerance is highly influenced by sex, age, education level, financial knowledge and financial satisfaction.
\end{abstract}

Keywords: sex, age, educational level, financial knowledge, financial satisfaction

\section{Introduction}

According to the Employees Provident Fund Malaysia (EPF, 2019), to those older couples and staying around Kuala Lumpur, Malaysia, they need around MYR 3,090 per month for their monthly living expenses such as food, housing, transport, utilities and others. For those older Malaysians retire with insufficient savings, it may motivate them to take higher risk and seek for investment with higher returns. As a result, financial risk tolerance has been a prominent study in issues related to financial management, investment and investor's investment decisions (Nguyen et al., 2016; Chng \& Hafinaz, 2019; Kanagasabai \& Aggarwal, 2020). Many studies have cited and defined financial risk tolerance as the maximum degree of uncertainty of an individual's willingness to accept risk or uncertainties when he or she is making a decision (Roszkowski \& Grable, 2010; Nobre et al., 2018). For example, risk-taking investors tend to consider more risky investments, thus indicating a relationship between financial risk tolerance and investment decisions (Nguyen et al., 2016; Kanagasabai \& Aggarwal, 2020). Previous studies can further support the influence of financial risk tolerance towards decision-making as it has been widely studied over the years (Shtudiner, 2018; Chng \& Hafinaz, 2019; Aeknarajindawat, 2020).

On the other hand, demographic characteristics (i.e., sex, age, marital status, income status, educational level, employment status, life expectation, and level of financial knowledge) were found to have a significant relationship with risk tolerance in multiple studies (Duasa \& Yusof, 2013; Kannadhasan, 2015; Samsuri et al., 2019). Kannadhasan (2015) examined a total of 778 retail investors through a survey conducted in India and found that men, young individuals, single individuals and self-employed individuals take on higher risks (risk takers). However, in some studies of the survey conducted in Malaysia and Kenya involving demographic characteristics and financial risk tolerance were found that older individuals are more risk tolerant (Onsomu et al., 2017; Chng \& Hafinaz, 2019). Hence, existing evidence may indicate that the differences between the cultural perspectives may play an essential role in risk tolerance.

According to "The Longevity Economy Outlook 2019" by AARP, a non-profit organization in the United States that examined issues affecting older people, the report has indicated an increase of $25.8 \%$ of new entrepreneurs aged 
around 55 to 64 years old in 2018; a rise of $11.0 \%$ when compared to $14.8 \%$ in 1996. According to the report, entrepreneurs around the age of 55 to 64 years old are more likely to venture into entrepreneurship to attain personal satisfaction and accumulate wealth. In this case, it may indicate individual risk tolerance increases in conjunction with their age. However, in a previous study by Chong et al. (2012) shows the demographic characteristic of age is insignificant to the financial risk tolerance of older urban Chinese in Malaysia. The result of the study may be insubstantial as many previous studies have proven otherwise and there are limited studies done on the risk tolerance of the older group of people in Malaysia. Interestingly, Chinese in the United States were found to be more risk tolerant than Americans which raises a question about the effect of ethnicity on risk-taking behavior (Fan \& Xiao, 2005). Nonetheless, as shown in "The Longevity Economy Outlook 2019" by AARP, the behavior of the older group of people has changed and has an increase in entrepreneurial activities, investment and the likelihood to undertake risky decisions.

In Malaysia, as the older group of people retire with insufficient savings, it may motivate them to take higher risk and seek for investment with higher returns. Hence, this study aims to assist the government in understanding the behavior of the older group in Malaysia with of focus on a certain ethnicity for a start towards suggesting ways of financial management and policy decisions. According to the Department of Statistics Malaysia (DOSM) (2020), Malaysia has a population of more than 32 million in the year 2019 and 22.8\% of the population are of Chinese ethnicity. Meanwhile, according to the Household Expenditure Survey Report 2019 by DOSM, about 68.0\% of Malaysian Chinese have a monthly household income of more than Malaysian Ringgit (MYR) 5,000 and about $45.0 \%$ of Malaysian Chinese have a monthly expenditure of more than MYR 5,000. As it signifies Malaysian Chinese have the spending power and willingness to spend, it highlights the importance of understanding older Malaysian Chinese's financial risk tolerance and financial management. Thus, this study aims to identify the demographic characteristics that influence the financial risk tolerance of older Chinese in Klang Valley, Malaysia.

\section{Literature Review}

\subsection{Sex}

Concerning sex and financial risk tolerance, Zandri and Sune (2018) found that there were significant differences between male and female risk tolerance. Meanwhile, findings from the field of study conclude that women are more risk-averse than men (Patti \& Rui, 2017). Rajesh (2018) and Thanki \& Baser (2019) stated that there is a significant difference in financial risk tolerance between the gender. This study was also found that the score for of male respondents was more than female respondents who indicated that male respondents had more risk tolerance (Prabha, 2016). In other studies, Chistina (2019), as well as Rui and Michael (2005), found that single men were more risk-tolerant than single women, as they commonly held a higher portion of their income in risky investment allocations. These findings contradict with results from a study by Ebrahim (2012), as the researcher found that the sex of individual investors and financial risk tolerance is independent of each other. Some researchers presented their findings and found no significant relationship in risk tolerance findings between men and women (Chng \& Hafinaz, 2019; Nosita et al., 2020). Meanwhile, Sandip and Ranjan (2015) found that men investors were more risk-averse than women investors.

\section{H1: There is a significant relationship between risk tolerance and sex.}

\subsection{Age}

Results of studies suggest that the demographic factor of age influences the risk tolerance of the individual investors. Holding other factors constant, Wang \& Hanna (1997) found that older people invest a larger proportion of their wealth in risky assets compared to young people. In one of the recent studies, Zandri and Sune (2018) found that investors had more risk tolerance with age. Investors who older than 50 years old are less risk-seeking compare to young investors from other age categories. Other authors, such as Sarfaraz and Yogeshwari (2017) indicated a significant difference in financial tolerance according to the age categories. A negative relationship is also proven between the investor's age and risk tolerance (Christina, 2019; Rahmawati et al., 2015). Zandri and Sune (2018) suggest a positive relationship between an investor's age and the percentage of the investment portfolio.

\section{H2: There is a significant relationship between risk tolerance and age.}

\subsection{Education}

Previous studies show sufficient evidence that an increase in the level of education of people will encourage the individual to take more financial risks than other investors who are coming from a lower level of education (Ebrahim, 2012; Rahmawati et al., 2015; Sandip \& Rajann, 2015). In contrast, Sarfaraz and Yogeshwari (2017) and Bashir et al. (2013) stated that education is not a significant factor in the risk tolerance of an individual. Daoud et al. 
(2020) suggested vocational education in his study to promote education by reducing the gender gap in entrepreneurship to encourage healthier levels of risk tolerance in the society.

H3: There is a significant relationship between risk tolerance and education level.

H3a: There is a significant relationship between risk tolerance and not educated.

$\mathrm{H} 3 \mathrm{~b}$ : There is a significant relationship between risk tolerance and primary education.

H3c: There is a significant relationship between risk tolerance and secondary education.

\subsection{Financial Knowledge}

Previous research is consistent in concluding that individuals with better financial understanding, experience, and knowledge will lead them to have a higher risk tolerance than others. Similar results are tracked in Christina (2019), Fernandes et al. (2014), Loke (2015), Nguyen et al. (2016), Samsuri et al. (2019) and Wisudanto and Zidni (2016) found that improving the understanding of the financial product is a critical component to make the correct and right option in regard to financial decision making. In general, better educated men were found to have higher financial risk tolerance from a study in Pakistan (Shah et al., 2020). Wang (2009) strongly suggested in his study that objective knowledge and subjective knowledge on finance are positively correlated with the level of risk-taking. In contrast, Ivona et al. (2016) argues that risk appetite does not depend on the level of investor's knowledge and awareness of finance and economics.

H4: There is a significant relationship between risk tolerance and financial knowledge.

\subsection{Financial Satisfaction}

Previous studies have tracked two components of financial satisfaction (level of income and wealth) are significantly to measure risk tolerance (Chong et al., 2014; Chong, et al., 2017; Muhammad \& Hafiq, 2014; Chng \& Hafinaz, 2019). Furthermore, Bertha et al. (2018) proved that there is a significant positive relationship between personal income levels and the variable of financial risk tolerance. Besides that, Praba (2016) also indicates that the level of individual's risk tolerance increases in a synchronized manner with the individual's wealth and earnings. Moreover, Sandip and Ranjan (2015) mentioned in their study that higher income and savings also will lean towards decreased risk aversion. However, some results from different studies suggest a negative impact of income on the level of risk tolerance (Rajesh, 2018). This is due to some of the lower-income and wealthy investors keen to tolerate higher risk when they decide in certain investment products, which can increase their wealth. A study done in South Africa found that life satisfaction significantly affects risk tolerance (Ferreira \& Dickason-Koekemoer, 2020).

H5: There is a significant relationship between risk tolerance and financial satisfaction

\section{Method}

In this study, the targeted sample was Chinese individuals who aged 50 years old or above and reside in the state of Selangor, Malaysia. The study employed convenience sampling and cross-sectional survey questionnaires from January to February 2020 and face-to-face interviews to collect the required data and the questionnaire features different areas: socio-demographic characteristics, risk tolerance, financial knowledge and financial satisfaction of the respondents. The dependent variable in this study refers to the financial risk tolerance of the older Malaysian Chinese, where; low scoring of risk tolerance of an individual indicates the tendency of being risk-averse, while high scoring of risk tolerance suggests the tendency of being risk-taker. On the other hand, the independent variables in this study were sex (dummy: male and female), age (ratio), an education level (dummy: no schooling, primary school, secondary school, and above secondary school level), financial knowledge (Likert scale: 1 - strongly disagree to 7 - strongly agree) and financial satisfaction (Likert scale: 1 - very unsatisfactory to 7 - very satisfactory). The survey manages to accumulate a total of 280 Chinese respondents with an age of 50 or above. The descriptive analysis of the respondents' demographic profile is shown in Table 1.

Table 1. Profile of respondents

\begin{tabular}{lll}
\hline Characteristics & $\begin{array}{l}\text { Percentage } \\
(\%)\end{array}$ & $\begin{array}{l}\text { Sample Size } \\
(\mathrm{n})\end{array}$ \\
\hline Sex & & \\
Male & 42.9 & 120 \\
\hline
\end{tabular}




\begin{tabular}{lll}
\hline Female & 57.1 & 160 \\
\hline Age Group & 65.7 & 184 \\
$50-59$ & 23.9 & 67 \\
$60-69$ & 10.4 & 29 \\
70 or over & & \\
\hline Marital Status & 76.8 & 215 \\
Currently Married & 17.1 & 48 \\
Widowed & 6.1 & 17 \\
Others & & \\
\hline Educational Level & 7.5 & 21 \\
Not Educated & 23.6 & 66 \\
Primary Education & 37.1 & 104 \\
Secondary Education & 31.8 & 89 \\
A-level, Certificate, Diploma, Degree & 100.0 & 280 \\
\hline Number of Respondents & & \\
\hline
\end{tabular}

In this research, the risk tolerance statements were mainly adapted from Chong et al. (2012) and Grable and Joo (2004). Table 2 shows the risk tolerance construct was checked using the reliability test and the Cronbach's Alpha is more than 0.8 while the mean score of risk tolerance is $2.95(1=$ strongly disagree and $7=$ strongly agree $)$ and the standard deviation is 1.13 .

Table 2. Descriptive statistics on the contract and cronbach's Alpha

\begin{tabular}{|c|c|c|c|c|c|c|c|c|c|c|}
\hline Statement & $\begin{array}{l}\mathrm{I} \\
\%\end{array}$ & $\begin{array}{l}\text { II } \\
\%\end{array}$ & $\begin{array}{l}\text { III } \\
\%\end{array}$ & $\begin{array}{l}\mathrm{IV} \\
\%\end{array}$ & $\begin{array}{l}\mathrm{V} \\
\%\end{array}$ & $\begin{array}{l}\mathrm{VI} \\
\%\end{array}$ & $\begin{array}{l}\text { VII } \\
\%\end{array}$ & $\begin{array}{l}\text { Total } \\
\%\end{array}$ & $\begin{array}{l}\text { Mean } \\
\text { Score }\end{array}$ & $\begin{array}{l}\text { Standard } \\
\text { Deviation }\end{array}$ \\
\hline $\begin{array}{l}\text { In term of investing, } \\
\text { returns are more } \\
\text { important than safety }\end{array}$ & 20.7 & 56.4 & 10.0 & 6.1 & 4.3 & 1.8 & 0.7 & 100.0 & 2.25 & 1.16 \\
\hline $\begin{array}{l}\text { I am more comfortable } \\
\text { putting my money in a } \\
\text { stock market than in } \\
\text { the bank account }\end{array}$ & 13.6 & 33.2 & 24.3 & 9.6 & 9.3 & 8.9 & 1.1 & 100.0 & 2.99 & 1.53 \\
\hline $\begin{array}{l}\text { I am more comfortable } \\
\text { putting my money in a } \\
\text { mutual fund than in the } \\
\text { bank account }\end{array}$ & 15.7 & 32.5 & 21.4 & 11.1 & 9.6 & 8.9 & 0.7 & 100.0 & 2.96 & 1.54 \\
\hline $\begin{array}{l}\text { I am more comfortable } \\
\text { putting my money in a } \\
\text { bond than in the bank } \\
\text { account }\end{array}$ & 16.1 & 29.3 & 18.6 & 15.0 & 8.6 & 9.3 & 3.2 & 100.0 & 3.11 & 1.67 \\
\hline $\begin{array}{l}\text { When I think of the } \\
\text { word "Loss" the term } \\
\text { "Risk" comes to mind } \\
\text { immediately }\end{array}$ & 13.9 & 35.4 & 20.4 & 17.1 & 6.8 & 5.7 & 0.7 & 100.0 & 2.88 & 1.41 \\
\hline $\begin{array}{l}\text { Making money in } \\
\text { stocks and bonds is not } \\
\text { based on luck }\end{array}$ & 19.3 & 38.6 & 10.4 & 20.7 & 7.5 & 3.2 & 0.4 & 100.0 & 2.70 & 1.39 \\
\hline
\end{tabular}




\begin{tabular}{llllllllllll}
\hline $\begin{array}{l}\text { I have a full of } \\
\text { knowledge to be a } \\
\text { successful investor }\end{array}$ & 8.9 & 24.3 & 30.0 & 13.9 & 14.6 & 7.5 & 0.7 & 100.0 & 3.26 & 1.42 \\
\hline $\begin{array}{l}\text { Investing is not } \\
\text { difficult to understand }\end{array}$ & 5.4 & 24.6 & 26.8 & 20.7 & 11.8 & 8.6 & 2.1 & 100.0 & 3.43 & 1.44 \\
\hline Risk Tolerance & & & & & & & $\mathrm{n}=280$ & 2.95 & 1.13 \\
\hline Cronbach's Alpha & 0.908 & & & & & & & \\
\hline
\end{tabular}

Note: I (strongly disagree), II (disagree), III (somewhat disagree), IV (neither disagree nor agree), V (somewhat agree), VI (agree), and VII (strongly agree).

\section{Discussion}

Before the regression results were performed, preliminary analyses were conducted to ensure no serious violation of the assumptions of normality, linearity, multicollinearity, homoscedasticity and autocorrelation. From Table 3, these regression results showed that the model is significant ( $\mathrm{F}$-stat $=17.777$ and significant at $1 \%$ level) with the $\mathrm{R}^{2}$ value of $30.1 \%$. Out of the seven independent variables, four variables (i.e., sex, age, secondary education and financial satisfaction) showed a significant relationship with the dependent variable (risk tolerance) at $1 \%$ level and the financial knowledge was found to associate with the risk tolerance at $10 \%$ level as compared to the previous study by Chong et al. (2012). In general, previous research shows that independent variables such as sex, an education level (primary and secondary educations) and financial knowledge have statistically significant at $1 \%$ level with the risk tolerance of an individual.

Based on the recent study regarding risk tolerance of older Chinese in Klang Valley, Malaysia, the results show that sex and secondary education level remains to be statistically significant at $1 \%$ confidence level to risk tolerance of the older Malaysian Chinese while financial knowledge has a confidence level of $10 \%$. Furthermore, variables such as age and financial satisfaction were found to be statistically significant at $1 \%$ confidence level towards risk tolerance in the recent study on older Malaysian Chinese.

Table 3. Regression of risk tolerance on demographic characteristics

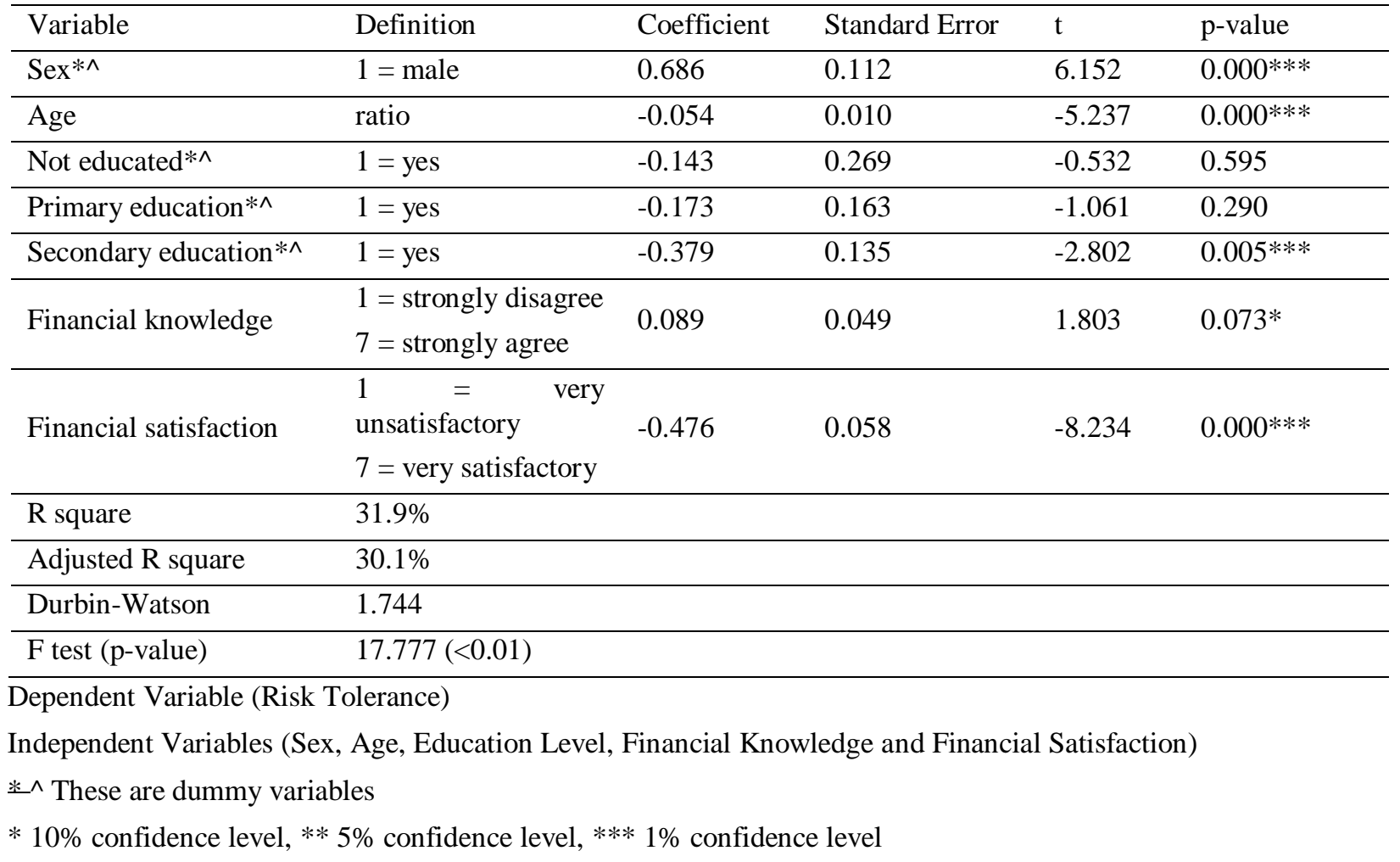


The demographic characteristics results of this study show that sex has a positive coefficient $(0.686)$ and the hypothesis $\mathrm{H} 1$ is supported at $1 \%$ level, indicating that male tends to be risk-taking compared to females (Chong et al., 2012; Kannadhasan, 2015; Nguyen et al., 2016; Patti \& Rui, 2017; Prabha, 2016; Rajesh, 2018; Zandri \& Sune, 2018). This may be due to male respondents have better financial knowledge and stronger financial ability as compared to female respondents and make them be more confident to accept high-risk products as constructed with the female.

In the case of the age variable, the result has shown that the level of risk tolerance of an individual decrease as the individual age (coefficient of -0.054), and the hypothesis $\mathrm{H} 2$ is supported at $1 \%$ level; contradicting with the previous result as age insignificant to risk tolerance in the study by Chong et al. (2012). Nonetheless, some studies found that older individuals have lower risk tolerance (Christina, 2019; Zandri \& Sune, 2018) as while Zandari and Sune (2018) suggest that older individuals held riskier stocks and they may have gained experience to choose the best stocks for their portfolio.

As for education level, the results of this study were found to be similar to the previous study by Chong et al. (2012) where older Malaysian Chinese with secondary education level have a negative coefficient (-0.379) with risk tolerance level and the hypothesis $\mathrm{H} 3 \mathrm{c}$ is supported at $1 \%$ level; meanwhile older Malaysian Chinese without any education and primary education do not influence their risk tolerance level; hypothesis $\mathrm{H} 3 \mathrm{a}$ and $\mathrm{H} 3 \mathrm{~b}$ are not supported. This indicates that individuals with higher education levels are more skewed into towards risk-tolerant compared to individuals with secondary education or below. The findings were found to be similar to other studies where highly educated people tend to have a higher risk tolerance level since losses from the investment will not significantly affect their standard of living (Nguyen et al., 2016; Sandip \& Rajann, 2015).

As for financial-related factors, financial knowledge was found to be positively (coefficient of 0.089 ) significant at $10 \%$ level of risk tolerance of older Malaysian Chinese, distinguishing from the previous result where financial knowledge significant at $1 \%$ confidence level and an individual with financial knowledge will reduce their risk tolerance (Chong et al. 2012). As a result, hypothesis H4 is supported, and this indicates the risk tolerance of the respondents is affected by their knowledge or literacy on finance or investment, similar to findings by Christina (2019), Samsuri et al. (2019) and Wisudanto and Zidni (2016). In terms of financial satisfaction, a recent study found the variable to be negatively related (coefficient of -0.476) to risk tolerance of the respondents and hypothesis $\mathrm{H} 5$ is supported at the $1 \%$ level. In this case, it indicates the respondents that are financially healthy and free from worries are skewed towards risk averse. This may occur due to their financial stability and no point in having a high-risk action, and this statement is supported by Sandip and Ranjan (2015) and Rajesh (2018).

\section{Conclusion}

The past studies revealed that demographic parameters such as gender, age, education, income, and occupation had been the interest to researchers as independent variables shaping the investor's financial risk tolerance (Mishra \& Mishra, 2014). However, the relationships between the selected demographic variables and financial risk tolerance were found inconsistent, therefore requiring more investigations (Shah et al., 2020). With growing concern on the ageing adult in Malaysia, this study is the second attempt to analyses the relationship between sex, age, education level, financial knowledge and financial satisfaction towards financial risk tolerance of the older Malaysia Chinese. Uniquely, this study includes the residency of an investor (urban) as a criterion in choosing respondents. The results from this study have revealed selected demographic factors which could influence individual preferences as well as their financial decisions, including investment decisions. Some people, therefore, have a lower risk tolerance, while others have a high-risk tolerance with some having a specific appetite for their risk, depending on the financial characteristics. The findings of the study are consistent with the previously drawn conclusion that older Chinese men were more risk-tolerant than females. More studies are needed to address the issue of why women tend to be risk-averse, especially in the Chinese community. Despite the increasing participation of women in the high-income workforce, there is still a low volume of females that invest in high-risk portfolios. This phenomenon leads to future work on understanding risk-taking behavior among older Chinese females. Comparing the results with the previous study (Chong et al., 2012), the age factor seems to influence an investment decision. The negative relationship indicates that older age respondents seem to be risk averse. This result is an interesting finding, as it is in contrary to what we know from previous findings. Besides, these results suggest that secondary educated, experienced and strong financial knowledge equipped senior citizens are reluctant to invest in high-risk portfolios. Next, financial institutions and government agencies should focus on increasing financial awareness, for senior citizens by conducting related education projects, detailing areas that people do not understand. The main limitation of this study only involved respondents from urban older Malaysia Chinese financial risk tolerance. Therefore, this research 
suggested that future researchers could survey semi-urban and rural areas in Malaysia. Besides, future studies also can investigate the risk tolerance of other ethnicities in Malaysia, like Sahm (2012) who found systematic differences from individuals of different races. Cultural differences may also affect risk tolerance as noted by Pyles et al. (2016), but its actual translation into investment decision is yet to be confirmed. Several other factors identified by Fang et al. (2020), such as wealth accumulation and prior experience with famine can be included as it may contribute to understanding better risk tolerance and risk-taking behaviors.

\section{References}

AARP. (2019). The longevity economy outlook. Retrieved from https://www.aarp.org/content/dam/aarp/research/surveys_statistics/econ/2019/longevity-economy-outlook.doi.1 0.26419-2Fint.00042.001.pdf

Aeknarajindawat, N. (2020). The combined effect of risk perception and risk tolerance on investment decision making. Journal of Security and Sustainability, 9(3), 807-818. https://doi.org/10.9770/jssi.2020.9.3(7)

Bashir, T., Uppal, S. T., Hanif, K., Yaseen, S. M., \& Saraj, K. (2013). Financial risk tolerant attitude: Empirical evidence from Pakistan. European Scientific Journal, 9(19), 200-209.

Bertha, S. S., Yohanes, K. N., \& Putu, A. M. (2018). Demography factors, financial risk tolerance and retail investors. 15th International Symposium on Management (INSYMA2018). Advances in Social Science, Education and Humanities Research (ASSEHR), 186, 80-83.

Chng, L. Q., \& Hafinaz, H. (2019). The factors affecting Malaysian investment risk tolerance for retirement plans. International Journal of Recent Technology and Engineering, 7(5S), 181-189.

Chong, S. C., Cheong, W. W., Sia, B. K., \& Ng, K. K. (2012). Perception of financial rik tolerance of older Urban Chinese in Malaysia. International Journal of Academic Research, 4(3), 28-34.

Chong, S. C., Lim, C. S., \& Wong, H. C. (2014). Financial satisfaction, resource transfers and bequest motives among Malaysia's urban older adults. Australian Journal of Basic and Applied Sciences, 8(8), 15-33.

Chong, S. C., Sia, B. C., Cheong, W. W., \& Jalaludin, F. W. (2017). Factors affecting attainment of ideal retirement income among retirees. Pertanika Journal of Social Science and Humanities, 25(S), 15-28.

Christina, H. W. (2019). The effect of demographic characteristics on an individual's financial risk tolerance. 2019 Academic Research Colloquium for Financial Planning and Related Disciplines. https://doi.org/10.2139/ssrn.3257904

Daoud, Y. S., Sarsour, S., Shanti, R., \& Kamal, S. (2020). Risk tolerance, gender and entrepreneurship: the palestinian case. Review of Development Economics, 24(3), 766-789. https://doi.org/10.1111/rode.12634

Department of Statistics Malaysia. (2020). Current population estimates, Malaysia, 2020. Retrieved from https://www.dosm.gov.my/v1/index.php?r=column/cthemeByCat\&cat=155\&bul_id=OVByWjg5YkQ3MWFZR TN5bDJiaEVhZz09\&menu_id=L0pheU43NWJwRWVSZklWdzQ4TlhUUT09

Duasa, J., \& Yusof, S. A. (2013). Determinants of risk tolerance on financial asset ownership: a case of Malaysia. International Journal of Business and Society, 14(1), 1-16.

Ebrahim, K. S. (2012). An empirical analysis of financial risk tolerance and demographic. Features of Individual Investors. Procedia Economics and Finance, 2, 109-115. https://doi.org/10.1016/S2212-5671(12)00070-6

EPF. (2019). Annual Report 2018.2 Retrieved https://www.kwsp.gov.my/documents/20126/f4d7f36f-ff1f-5017-f94d-8bfdf1ffc644

Fan, J. X., \& Xiao, J. J. (2005). A Cross-cultural Study in Risk Tolerance: Comparing Chinese and Americans. TCAI Working Paper 5-3. https://doi.org/10.2139/ssrn.939438

Fang, M., Li, H., \& Wang, Q. (2020). Risk tolerance and household wealth - evidence from Chinese households. Economic Modelling. https://doi.org/10.1016/j.econmod.2020.02.029

Fernandes, D., Lynch, J. G., \& Netemeyer, R. G. (2014). Financial literacy, financial education and downstream financial behaviors. Management Science, 60(8), 1861-1883. https://doi.org/10.1287/mnsc.2013.1849

Ferreira, S., \& Dickason-Koekemoer, Z. (2020). A structural equation model of financial risk tolerance in South Africa. Cogent Business \& Management, 7(1). https://doi.org/10.1080/23311975.2020.1811595 
Grable, J. E., \& Joo, S. H. (2004). Environmental and biopsychosocial factors associated with financial risk tolerance. Financial Counseling and Planning, 15(1), 73-82.

Kanagasabai, B., \& Aggarwal, V. (2020). The mediating role of risk tolerance in the relationship between financial literacy and investment performance. Colombo Business Journal, 11(1), 83-104. https://doi.org/10.4038/cbj.v11i1.58

Kannadhasan, M. (2015). Retail investors' financial risk tolerance and their risk-taking behaviour: the role of demographics as differentiating and classifying factors. IIMB Management Review, 27(3), 175-184. https://doi.org/10.1016/j.iimb.2015.06.004

Loke, Y. J. (2015). Financial knowledge and behaviour of working adults in Malaysia. Margin: The Journal of Applied Economic Research, 9(1), 18-38. https://doi.org/10.1177/0973801014557392

Mishra, S., \& Mishra, M. (2014). Financial risk tolerance: a literature review. Siddhant-A Journal of Decision Making, 14(1), 10. https://doi.org/10.5958/j.2231-0657.14.1.002

Muhammad, N. S., \& Hafiz, M. I. (2014). The effect of demographic factors on the behavior of investors during the choice of investment: evidence from twin cities of Pakistan. Global Journal of Management and Business Research, 14(3), 47-56.

Nguyen, L. T. M., Gallery, G., \& Newton, C. (2016). The influence of financial risk tolerance on investment decision-making in a financial advice context. Australasian Accounting, Business and Finance Journal, 10(3), 3-22. https://doi.org/10.14453/aabfj.v10i3.2

Nobre, L. H. N., Grable, J. E., Silva, W. V. da., \& Nobre, F. C. (2018). Managerial risk-taking: a conceptual model for business use. Management Decision, 56(11), 2487-2501. https://doi.org/10.1108/MD-09-2017-0892

Nosita, F., Pirzada, K., Lestari, T., \& Cahyono, R. (2020). Impact of demographic factors on risk tolerance. Journal of Security \& Sustainability Issues, 9(4), 1327-1336. https://doi.org/10.9770/jssi.2020.9.4(18)

Onsomu, Z. N., Kaijage, P. E., Aduda, J., \& Iraya, C. (2017). Risk tolerance, demographics and portfolio performance. Journal of Business and Economic Policy, 4(3), 69-74.

Patti, J. F., \& Rui, Y. (2017). Gender differences in financial risk tolerance. Journal of Economic Psychology, 61, 191-202. https://doi.org/10.1016/j.joep.2017.03.006

Prabha, S. (2016). Financial risk tolerance and the influence of socio-demographic characteristics of retail investors. ISBR Management Journal, 1(1), 65-79.

Pyles, M. K., Li, Y., Wu, S., \& Dolvin, S. D. (2016). Cultural influences on risk tolerance and portfolio creation. Journal of Behavioral and Experimental Finance, 9, 43-55. https://doi.org/10.1016/j.jbef.2016.01.001

Rahmawati, M., Dileep, K., Meyland, K., Farhan, J., \& Saqib, M. (2015). Determinants of the Risk Tolerance of Individual Investors. International Journal of Economics and Financial Issues, 5(Special Issue), 373-378.

Rajesh, M. (2018). Financial literacy, risk tolerance and stock market participation. Asian Economic and Financial Review, 8(12), 1457-1471. https://doi.org/10.18488/journal.aefr.2018.812.1457.1471

Roszkowski, M. J., \& Grable, J. E. (2010). Gender differences in personal income and financial risk tolerance: how much of a connection?. The Career Development Quarterly, 58(3), 270-275. https://doi.org/10.1002/j.2161-0045.2010.tb00192.x

Rui, Y., Michael, S. G., \& Sherman, D. H. (2005). The effect of gender and marital status on financial risk tolerance. Journal of Personal Finance, 4(1), 66-85.

Sahm, C. R. (2012). How much does risk tolerance change?. The Quarterly Journal of Finance, 2(04), 1250020. https://doi.org/10.1142/S2010139212500206

Samsuri, A., Ismiyanti, F., \& Narsa, M. (2019). Effects of risk tolerance and financial literacy to investment intentions. International Journal of Innovation, Creativity and Change, 10(9), 40-54.

Sandip, C., \& Ranjan, D. (2015). Demographic and socioeconomic impact on risk attitudes of the Indian investors-an empirical study. Asian Economic and Financial Review, 5(4), 601-623. https://doi.org/10.18488/journal.aefr/2015.5.4/102.4.601.623

Sarfaraz, A., \& Yogeshwari, P. (2017). A study of effect of demographic characteristics on financial risk tolerance of individual investors. International Journal of Management Studies, 4(3), 118-128. 
Shah, N. H., Khalid, W., Khan, S., Arif, M., \& Khan, M. A. (2020). An Empirical Analysis of Financial Risk Tolerance and Demographic Factors of Business Graduates in Pakistan. International Journal of Economics and Financial Issues, 10(4), 220-234. https://doi.org/10.32479/ijefi.9365

Shah, N. H., Khalid, W., Khan, S., Arif, M., \& Khan, M. A. (2020). An empirical analysis of financial risk tolerance and demographic factors of business graduates in Pakistan. International Journal of Economics and Financial Issues, 10(4), 220-234. https://doi.org/10.32479/ijefi.9365

Shtudiner, Z. (2018). Risk tolerance, time preference and financial decision-making: differences between self-employed people and employees. Modern Economy, 9(12), 2150-2163. https://doi.org/10.4236/me.2018.912133

Thanki, H., \& Baser, N. (2019). Interactive impact of demographic variables and personality type on risk tolerance. Emerging Economy Studies, 5(1), 42-54. https://doi.org/10.1177/2394901519825924

Wang, A. (2009). Interplay of investors' financial knowledge and risk taking. The Journal of Behavioral Finance, 10(4), 204-213. https://doi.org/10.1080/15427560903369292

Wang, H., \& Hanna, S. D. (1997). Does risk tolerance decrease with age?. Financial Counseling and Planning, 8(2), 27-32.

Wisudanto, M. S., \& Zidni, M. (2016). Income, financial risk tolerance, financial literacy and participation in capital market. International Conference on Organization Innovation: At Hall of Meeting Center, Beijing China.

Zandri, S., \& Sune, J. F. (2018). The effect of age and gender on financial risk tolerance of South African investors. Investment Management and Financial Innovations, 15(2), 96-103. https://doi.org/10.21511/imfi.15(2).2018.09

\section{Copyrights}

Copyright for this article is retained by the author(s), with first publication rights granted to the journal.

This is an open-access article distributed under the terms and conditions of the Creative Commons Attribution license (http://creativecommons.org/licenses/by/4.0/). 